\title{
Families in Transition: The Lived Experience of Parenting a Transgender Child
}

\author{
Linda D. Wagner, EdD, MSN' (iD, \\ and Elizabeth Armstrong, DNP, CNE'
}

\begin{abstract}
Research exploring the parents' experience of their child undergoing gender transition is almost nonexistent. However, as the number of individuals who identify as transgender increases, gender identity will continue to evolve; therefore, supporting families of these individuals is paramount. Parents of transgender children were interviewed and yielded five themes: (a) It Rocks Your World; (b) Dancing Around in a Way that Doesn't Distance; (c) Your Child Is Still Your Child; (d) Worrying About the Future; and (e) Transformational: Finally an Answer. These themes begin to identify the complex nature and struggles parents face as they encounter the emotional and physical aspects of their child's gender transition. The findings raise awareness of the parents' perspective, provide a better understanding of the complex family issues that occur, and provide nursing suggestions on how to continue to work to facilitate "healthy families" and promote cultural sensitivity.
\end{abstract}

\section{Keywords \\ transgender individuals, parents' experience, transition, cultural care}

Many nurses find it difficult discussing sexual identity or sexual preferences with patients and may often discriminate care based on these findings. According to the American Nurses Association (ANA, 2018) discrimination, denial of care, barriers accessing care, and provider's intolerance are associated with a lack of understanding and knowledge related to the needs of the transgender individual. Discrimination may be associated with prejudice on the part of the nurse due to a lack of knowledge regarding sexual orientation, expression, and/or gender identity. If transgender patients perceive they do not fit into a heteronormative culture, they may encounter bias, which results in lack of seeking health care treatment (Landry, 2017).

Research on nursing care of the transgender individual is emerging as incidence and reporting of this population have increased. However, a review of the recent nursing literature found a paucity of research on parents' experience of having a child undergo gender transition. Approximately 1.4 million adults, or $0.6 \%$ of the entire population in the United States, now identify as transgender (A. R. Flores et al., 2016). The ANA (2018) Position Statement on nurse advocacy for LGBTQ + (lesbian, gay, bisexual, transgender, queer, or questioning) population notes how ill-prepared many nurses are while caring for this population. This qualitative study explored the issue of transgender individuals from the parent's perspective and how nurses can support and treat the individual while also honoring the role that parents play in this transition process.

Of the studies conducted on parents and transgender children, several concluded that the experience of gender transition is a family process, affecting all members (Alegria, 2018; Kuvalanka et al., 2014). Additional studies reported parents' feelings related to their child's gender transition and new identity as a profound loss or ambiguous loss and an uncertainty (Coolhart et al., 2018; Gray et al., 2016; Simons et al., 2013; Wahlig, 2015). Transgender individuals and families reported that when seeking health care, they faced extraordinary levels of ill-treatment and scrutiny (James et al., 2016; Kuvalanka et al., 2014; Schimmel-Bristow et al., 2018).

Dierckx and colleagues (2016) conducted a literature review on family aspects of gender transition and found that studies were nearly nonexistent. Their search uncovered 11 studies that were reviewed. The authors summarized their review with the following findings: raising a transgender

'University of Bridgeport, CT, USA

Corresponding Author:

Linda D. Wagner, Associate Professor, School of Nursing, University of Bridgeport, 60 Lafayette St., Bridgeport, CT 06460, USA.

Email: Lwagner9092@gmail.com 
youth can be challenging and may involve feelings of guilt, shame due to social stigmatization, grief, and relational conflict; the importance of a positive relationship between the parent and the child; and that the adjustment and reaction of the parent is not a static situation but a process.

Simons and colleagues (2013) interviewed 66 transgender youth at a children's hospital clinic utilizing the family subscale of the Multidimensional Scale of Perceived Social Support, a Quality of Life Survey, and the Beck Depression Inventory. Their results showed that greater parental support was significantly associated with higher life satisfaction, lower perceived burden of being transgender, and fewer depressive symptoms.

It is also noteworthy to highlight the negative impact that unsupportive families may have on transitioning individuals. Both lack of support and lack of acceptance place them at risk of experiencing family rejection, suicide, discrimination, and ultimately reluctance to seek out health care services (Alegria, 2018). In addition, stigma from families or the larger community can influence the psychological wellbeing of transgender individuals and thus create negative outcomes (Cicero \& Wesp, 2017; Gray et al., 2016).

While the majority of care that nurses provide is to individuals, it is imperative that nurses view the individual within the context of family. They must be sensitive to the rights and needs of both the individual and their families when they seek health care treatment. The ANA advocates for trust, compassionate care, and respect for all individuals and thus rejects all discrimination and intolerance. In addition, the ANA (2018) advocates families of LGBTQ + have equal opportunity when it comes to visiting privileges and access to their loved ones seeking care or when hospitalized.

Although this may cause controversy when considering the Health Insurance Portability and Accountability Act (HIPAA) and who has a right to know about the health care concerns of the individual, nurses who consider family as important will find ways to employ systems theory in considering a best course of interventions for the individual. One component of the systems theory is that changes affect the individual and family simultaneously (Wright \& Leahey, 2013). One of the goals should always be to promote family health, to the best extent possible. Experiences with uninformed health professionals and lack of professional support can cause extreme stress for transgender individuals, parents, and families of these individuals. Alegria (2018) found in her qualitative study of 12 parents of transgender individuals that when supported by their families and their environments, transgender individuals demonstrated positive mental health and higher life satisfaction. Because of this, the parents saw their children as happier and more socially engaged after transition. Thus, it is essential that parents of transgender individuals be supported and valued as well.

Chick and Meleis (1986) first published a concept analysis on transition 30 years ago. As this theory has evolved over the years, the essence of a successful transition and outcome has remained consistent. Meleis et al. (2000) further developed this mid-range transition theory and highlighted several central concepts. As a complex process, these central concepts have been identified as the nature of the transition, transition conditions that can facilitate or inhibit transition, patterns of response, and nursing therapeutics.

As someone parenting a daughter to now parenting a son (or vice versa), there is the creation of new meanings and perceptions of that relationship. It may take several years to fully appreciate and embrace this new relationship and let go of the old one. According to transition theory, the process indicators of feeling connected, interacting, being situated, and developing confidence and coping can facilitate the outcomes of mastery and integrative identities (Meleis et al., 2000). As nurses work with and assess individuals and families, there will be critical points that require the nurse's "attention, knowledge, and experience in different ways" (Meleis et al., 2000, p. 21). Transition affects both the individual and the family system simultaneously.

As a parent works through the issues of the child's gender change and processes how new relationships are formed, there is an additional process of loss and grief (Coolhart et al., 2018). Parents may also be dealing with conflicting allegiances, such as do I choose my child or do I choose my church's or societies' expectations? Parents often grieve the loss of the child's former gender identity and resulting parent-child relationship (e.g., parent-daughter relationship to now a parent-son relationship). Health care providers can work to support both individuals through this process as communication, intimacy, social activities, and shared time together will all change as the gender transition evolves.

This qualitative research study begins to explore the experience of parents who have children who are transgender. The focus is on the context of the family rather than the broader social context of school or community. The purpose of the study is, "What is the experience of parenting a transgender child?" This study attempts to raise awareness of the parent's perspective and provide a better understanding of the complex family issues that occur with transition. Results can then be utilized to enhance the health of transitioned individuals in the context of the family unit.

\section{Method}

\section{Methodology}

This study used qualitative descriptive phenomenology to explore the human experience of parents whose children have undergone gender transition. The goal was to explore the holistic meaning of the parent's lived experiences and seek similarities in their lived experiences; thus, descriptive phenomenology was selected. This study seeks to add to the nursing knowledge related to families with children undergoing gender transition so that nurses can provide culturally competent care to families and children who are undergoing 
gender transition. Parents need to be supported due to many challenges in society, such as inadequate health care and discrimination, to optimize families with transgender children (Alegria, 2018).

Traditionally, gender has been expressed in binary terms male and female (Saewyc, 2017). As health professionals experience more gender fluidity in practice, there is a need to increase knowledge of self-identification. Pinkerton (2016) interviewed Katy Tierney, a nurse practitioner working with transgender individuals, who commented that "Gender is a common lived experience for all of us and an essential part of how we operate in our worlds" (p. 21). For the purpose of this study, a person in transition is defined as "a person whose biologic anatomy does not correspond with their sexual identity and many have a desire to outwardly express the gender to which they identify" (Landry, 2017, p. 345). To express selfidentified gender, a person may pursue nonmedical actions such as name change, pronoun usage, and appearance alteration or they may seek out physical and/or physiological alteration through hormones or reconstructive surgery.

\section{Participants and Setting}

After approval by the University Human Subjects Council, parents were recruited through snowball sampling and word of mouth. In addition, a social worker from a local support group for parents of transgender children shared the flyer announcement. Potential participants were given an email or phone number of the researchers as a contact for interest in participation. Criteria for sample eligibility included (a) male or female, (b) parent of a transgender child who was 13 to 30 years of age, and (c) English speaking. Recruitment continued until data saturation was reached. While inclusion of both parents in the research study was encouraged, for the majority of parents interviewed, they noted that the other parent was not "ready" or interested in being a participant. The recruitment sample did include one family where both parents agreed to participate.

\section{Ethical Considerations}

The study was approved by the University Human Subjects Council. The study was explained, and a consent form was emailed electronically should the parent agree to participate. Participation in the interview signified consent to better establish anonymity. A brief demographic form was completed, and no identifying data were collected. Transcriptions and reporting of research findings used pseudonyms. No parents reported negative effects from interview participation, but a resource sheet was available to direct them to support organizations should one be requested.

\section{Data Collection}

The data were collected from fall 2017 through summer 2018 with both researchers participating in the interview process. To
Table I. Semi-Structured Interview Protocol.

I. Tell me about an experience where this transition has impacted the relationship between you and your child?

2. Tell me about some strategies that you have used to increase your understanding of transgender issues.

3. Describe for me an experience of a time that was special for you and __, before, and then after transition.

4. Tell me about a time when you had to share the news with a friend or a family member.

5. What is your most important concern about parenting a transgender person?

6. In what ways has the family been impacted? What do you want for your family?

7. Describe for me what "endings and beginnings" means to you?

Is there anything else you want to share?

maintain consistency between researchers, semi-structured interviews consisting of open-ended questions (see Table 1) were developed. Semi-structured interviews were chosen to allow the participants to share their experience and reflect on the transition of their child. The researchers networked with parents through word of mouth and a local support group for recruitment. In addition, snowball sampling was utilized.

All interviews were conducted using a pre-prepared interview guide and audiotaped. The interviews were conducted in private settings where privacy and confidentiality were maintained. Participants were encouraged to talk freely and to tell stories using their own words while being audiotaped. Each interview lasted approximately $45 \mathrm{~min}$ to $1 \mathrm{hr}$. The level of data saturation was determined by the researchers in a process carried out in parallel with data collection. The interviews were transcribed verbatim and analyzed following the naturalistic inquiry methodology by the researchers.

\section{Data Analysis}

The descriptive phenomenology method of inquiry, specifically Colaizzi's (1978) seven-step method, was used to guide data analysis. The seven steps include reading and rereading descriptions, extracting significant statements, formulating meanings, categorizing into clusters of themes and validating with original text, describing, returning to participants, and incorporating any changes based on the informants' feedback. The final step of this method is to pose a comprehensive paradigm of the themes that have emerged from the phenomenon studied (Wojnar \& Swanson, 2007).

Both authors conducted interviews, kept notes, and reviewed the transcripts individually to extract significant statements. The researchers immersed themselves in the data by listening to the audiotapes while reading the transcripts and then meeting regularly to review and discuss emerging themes across interviews. Significant statements that pertained to the experience were extracted and organized into five overarching themes. Trustworthiness and 
credibility were achieved through prolonged engagement, peer debriefings, member checking, and an audit trail. Member checking with two study participants provided validation of results.

\section{Results}

A purposive sample of 16 adult parents of transgender children between the ages of 13 and 30 years were interviewed. The demographic characteristics are described in Table 2. The majority (75\%) were female. Data analysis resulted in the emergence of five themes: (a) It Rocks Your World; (b) Dancing Around in a Way that Doesn't Distance; (c) Your Child Is Still Your Child; (d) Worrying About the Future; and (e) Transformational: Finally an Answer. Participants shared specific events and feelings leading to the five themes. Participants and their children have been given pseudonyms to maintain confidentiality.

\section{It Rocks Your World}

A common theme of the participants was the emotional impact that parents felt when first having discussions with their child regarding transgender issues. There was a range of emotions that parents shared when asked about what it first felt like when their child shared the news with them. Emotions described included shock, frustration, confusion, and being stunned. One mother commented,

Well, I kind of caught wind that something was going on about two months before he actually came out to us and I was scared, and I just wanted to pretend that it wasn't a thing. Then, once he came out to us, at first, I was hit by the idea that I had just lost my child, but I think that I got over it fairly quickly, because I made the decision in my head that he wasn't dead. He's still right there. It's the same kid.

Another stated,

Obviously, that was a life-changing moment. That day that he told me, "I think I'm actually a guy," we were standing in the kitchen ... . That was the first moment when he expressed something to me, and I think that it hit me like a bowling ball really. It was like, "What, where is that coming from?" There was that initial shock.

As the parents began to adjust to the transition of their child as transgender, emotions shifted more toward guilt at not recognizing cues earlier and mourning. They often commented that they were angry at themselves for not acknowledging their child's authentic gender earlier. One mother shared,

My husband was struggling a lot more with it. He had feelings of guilt, which it wasn't that he couldn't accept, he just felt guilty like "all these years I've had a son and I should have been more of a dad to a boy."
Table 2. Sociodemographics of Participants at Baseline.

\begin{tabular}{|c|c|c|}
\hline Baseline characteristic & $N=16$ & $\%$ \\
\hline \multicolumn{3}{|l|}{ Age, years } \\
\hline $40-49$ & 7 & 44 \\
\hline $50-59$ & 8 & 50 \\
\hline $60-65$ & I & 6 \\
\hline \multicolumn{3}{|l|}{ Relationship status } \\
\hline Single & 0 & \\
\hline Married & 10 & 63 \\
\hline Divorced & 6 & 37 \\
\hline \multicolumn{3}{|l|}{ Education } \\
\hline Higher secondary & 3 & 19 \\
\hline Associates & 1 & 6 \\
\hline Bachelors & 4 & 25 \\
\hline Masters & 7 & 44 \\
\hline Doctorate & 1 & 6 \\
\hline \multicolumn{3}{|l|}{ Religious affiliation } \\
\hline Yes & 9 & 57 \\
\hline No & 6 & 37 \\
\hline No answer & 1 & 6 \\
\hline \multicolumn{3}{|l|}{ Race } \\
\hline Hispanic & 0 & \\
\hline African American & 0 & \\
\hline White, non-Hispanic & 15 & 94 \\
\hline Asian & 0 & \\
\hline Other & 1 & 6 \\
\hline \multicolumn{3}{|l|}{ Relationship } \\
\hline Mother & 12 & 75 \\
\hline Father & 4 & 25 \\
\hline \multicolumn{3}{|c|}{ How long ago was the transition? } \\
\hline $0-2$ years & 6 & 37 \\
\hline 3-5 years & 7 & 44 \\
\hline $6+$ years & 3 & 19 \\
\hline \multicolumn{3}{|l|}{ Child } \\
\hline MTF & 4 & 25 \\
\hline FTM & II & 69 \\
\hline Gender nonbinary & I & 6 \\
\hline
\end{tabular}

MTF $=$ male to female; FTM $=$ female to male.

Another remarked,

I'm still mourning saying "my three boys." It was really hard for me to stop saying "boys get down here" or "my sons." It was really hard for me to form the words daughter and sister. That to me was ending the "group" in my house.

\section{Dancing Around in a Way That Doesn't Distance}

As the initial shock and varied emotional feelings started to subside, the participants often found themselves unsure as to how to act or what to say. They talked about the complicated process of adjusting to new pronouns or a change in dress while cautiously monitoring their child for ongoing signs of depression or other mental health issues. The carefully choreographed "dance" was an attempt to support all 
family members as they simultaneously addressed both their own feelings and their child's. While trying to understand and support their child, one parent remarked, "You have to give yourself permission to feel what you're feeling." They were in the midst of sharing the news with family and friends depending on how the transition was evolving. Comments such as "You are afraid if you are not onboard they will kill themselves" and "We have to get the pronouns right" or "Your goal is to keep the child alive and moving to a place where they can thrive again with the family intact" were common emotions expressed.

Struggling with vacillating intellectual and emotional feelings often left the participants unsure as to what to say or how to be supportive. While "giving yourselves permission to feel what you're feeling," the majority of parents' comments reflected this statement made by one father:

$\mathrm{J}$ (his wife) and I have our own dynamic to try to figure out, so somebody's got to take different roles, and that seemed to be the way it shaped up a bit. You know, not to say that I didn't have my own misgivings about it.

Trying to be supportive of your child while struggling with your own emotions was a frequent response that parents shared. One remarked,

The person that John wanted to be was very different from the daughter I had. But now I'm more aware that for him to build a new identity, he was terrified of how much I loved Susan, and he did not love Susan. He couldn't handle how much I loved my daughter and that was devastating for him.

\section{Your Child Is Still Your Child}

Regardless of all the varied emotions that these parents shared, the overarching theme was that "your child is still your child." There were several comments such as "I just look at him as my child, and I don't think of gender," "you just want your kids to be your kids, they are no longer transgender, she is who she is, they are your kids," or "I either have to get on this train, or the train is leaving without me. I wasn't about to lose my child." The parents wanted their children to be welcome and accepted as they are.

One parent summed it up nicely when he commented,

Gender is one of the least important things about my children. Happiness, relationships, intellectual growth, gender is pretty much down the list, but it's important to the child and it's their decision. My wife felt more loss than I did, I love both of my children, whatever their names are.

\section{Worrying About the Future}

A common theme among participants was the fact that there is still much stigma and discrimination surrounding transgender individuals. Parents described instances of their child being bullied for using different bathrooms, concerns as to where their children traveled, or college housing options. One parent remarked that "We have been trying to get him out there and to be ready when he gets out of high school and he goes to college. We want to help prepare him for different scenarios." Another stated, "He needs to learn how to deal with people that are not going to be happy about anything related to being transgender."

Along with personal safety, participants were very concerned about the long-term consequences of gender transition. Health-related long-term effects of this population are still being researched, and the parents were concerned about issues such as the effect of hormone replacement therapy, hysterectomies, top surgery, sperm storage, privacy and scheduling of physical and gynecological examinations, as well as romantic relationships and child-bearing. One mother shared her conflict with having her daughter transition to a male when she said,

What am I doing? I'm killing my daughter. And you are in a terrible spot, where you are trying to save your child, I'm trying to save my daughter's life, and my son is saying "if you do that, I won't make it."

Another participant shared a story about her son:

He would hold his urine and I was afraid he would get a urinary tract infection and that it would affect his health. He would hold his urine all day and sometimes even after school if he had theater or something like that. In addition, he began binding his breasts early and I was afraid this was not healthy for breast tissue and he would not take off the bindings at night because he did not want his "tumors" to remind him of his issues, or his body dysmorphia. Not to mention the implications of hormone therapy.

The children of our participants had a range of physical changes that they had undergone. Many were on hormone replacement therapy; some had had top surgery, a hysterectomy, or facial reconstruction.

\section{Transformational: Finally an Answer}

One of the research questions asked participants about describing what "endings and beginnings" meant for them. Their answers focused on depression, sadness, suicidal ideations, anger, and unhappiness that their children felt prior to transition and the remarkable transformation that was evident after the transition occurred. Words such as happy and approachable, more confident, well adjusted, and "true to himself" described their children after the transition. The parents talked about "the end of a lot of pain and bad things that were going on," "being totally engaged, not intimidated, laughing, very interactive," and "finally feeling like the person he wanted to be." One parent related a story of a conversation that she had with her son when she asked him 
"When did you really start thinking like this?" The son's response was "Probably from the time I was seven. I would go to bed every night and pray that I would be a boy when I woke up."

Another stated,

That person who was Mary, was a sad, lost, very hard person to reach. There were so many things that I don't miss about that person and I am so happy that Eric is who he is, because it's like a 180-degree difference, literally.

\section{Discussion}

The participants spoke extensively about both the emotional and intellectual struggle that they experienced as they supported their child through this transition process. For many parents, the child's initial depression, sadness, and anxiety were worse than the transition experience. As identified by Meleis et al. (2000), transition includes the creation of new meanings and perceptions, and as these parents grappled with the social and medical transition of their child, these new perceptions have overall led to the ability to "thrive again with the family intact," as one participant commented.

Several research studies support the wide range of emotions expressed by the participants, ranging from loss and grief, helplessness, fear about safety, and fear about the future (Coolhart et al., 2018; Dierckx et al., 2016; Kuvalanka et al., 2014). One participant summed it up nicely as "it wasn't the elephant in the room, it was the room" when describing the totality of the transition experience on the whole family.

Consistent with Coolhart et al.'s (2018) qualitative study of six parents of transgender male youth, parents in this study shared two common themes. The theme "Putting the child first" was similar to a finding in this project. To cope with the various feelings expressed, parents focused on placing their child as the highest priority. The six parents were concerned about the happiness and safety of their children. They also described "Transformation" as the "ability to finally see the child they had all along" (Coolhart et al., p. 38). The authors surmise that this may "help families become "unstuck" when dealing with feelings of ambiguous loss (Coolhart et al.).

Alegria (2018) in her study found that the 14 parents she interviewed were focused on the fact that their children were much happier after transition. Despite the relief that the children were happier, both Allegra and Gray et al. (2016) shared similar findings of "future uncertainty." This uncertainty consisted of both social (fears for safety) and self (fears for mental health and positive relationships). In the study of 11 White, economically and educationally privileged parents of gender-variant children, Gray et al. found that the parents came to "a developmental and dynamic understanding of children's GV [gender variant] that changed over time and, for some parents, remained fluid" (p. 135).
This study did not uncover any themes of "having a GV child changes relationships in the whole family" (Gray et al., 2016, p. 131). According to Meleis et al. (2000), the wellbeing of relationships in terms of family integration is an indicator of a successful transition and a healthy family system. Family systems theory would also support this finding; however, the focus of this study was on the parents' experience, and future studies may branch out to include siblings of children who have transitioned to obtain their experience.

The majority (81\%) of the study participants possessed a degree beyond high school. They were actively involved in trying to secure the best therapy, treatment, and success for their child. They were adept at being able to tease out the issues of adolescent development intermingled with gender questioning. The remark by one parent that "It has been mostly parenting a teen, not necessarily parenting a transteen. It's just parenting a teen that happens to be trans" captures the feelings of the majority of the parents interviewed regarding their relationship with their child.

\section{Limitations}

This study is one of the first to explore parents' journey as their child undergoes gender transition. Participants included fathers as well as mothers, from a range of backgrounds and family constellations. Although it would have been beneficial to interview both parents, often the other parent was not at a point where they were ready to share their experience. Several of the parents were from one parent support group in a relatively liberal state whose experiences may have been more positive, and this is recognized as a sign of limitation. Despite aggressive recruitment efforts, we were unable to recruit from non-White ethnic minorities, so findings may not be generalizable to this population. Expanding the advertisement to clinics that serve this population, or on internet support or chat sites, or advertising in other languages would have increased the diversity of the sample. It is worth noting that without money or privilege, many families may not have access to the option of transition.

\section{Implications for Family Nursing Practice and Future Research}

The notion of traditional gender identification is evolving; thus, nurses must understand the distinctive needs of the transgender population to provide competent, holistic, and safe care. Because the nurse-patient relationship is fundamental to nursing care in all health care settings, this relationship requires providing culturally competent and ethical care regardless of the person's gender. The education of nurses related to the unique health needs of this population is vital for providing best practice and holistic care (ANA, 2018). Several recent studies (Cicero \& Wesp, 2017; Kirkpatrick et al., 2015; Landry, 2017; McCann \& Brown, 
2019; Nicol et al., 2013) highlight the necessity for nursing education programs to include and enhance LGBTQ content in their curricula because many health care providers who were interviewed lacked the knowledge and skills to provide competent, culturally sensitive care to this population. Identification of strategies to raise nurses' competency in addressing the needs of transgender individuals and their families is imperative for better quality of life. The Code of Ethics for Nurses with Interpretive Statements (ANA, 2015) asserts, "The nurse practices with compassion and respect for the inherent dignity, worth, and unique attributes of every person" (p. 1).

According to James et al. (2016), one third of the survey respondents reported that when visiting a health care provider, they had experienced negativity. This was in the form of either verbal harassment or denial of treatment, in addition to intolerance and discrimination from health care providers. Most health care professionals are undereducated and lack knowledge about transgender health care issues, thus resulting in poor health care advice for the patient and family (Kuvalanka et al., 2014). Specifics include better knowledge regarding gynecological examinations, bathroom amenities, and appropriate language (Eliason, 2017). As one mother commented, a suggestion for health professionals working with these individuals regarding physical changes is "don't ask unless it is relevant to the current healthcare condition" (parent interview).

Suggestions from the participants, when asked about what health care professionals can do to improve care, ranged from encourage a support system, practice "zero reaction," to acknowledge that sometimes parents need a break from the totality of focus on their "transgender" world. Although this sample did not seem to express significant financial struggles, they did mention the financial impact of medical care, hair removal procedures, visits to sperm banks, and change in clothing needs as relevant issues.

Nursing's lack of knowledge related to this population's health care needs, in addition to caregiver intolerance that many LGBTQ + have experienced, leads to health disparities and discrimination. Strategies to address this include asking gender-neutral questions, identifying LGBTQ + sensitive resources, and training and education to improve knowledge and sensitivity with the goal of developing cultural competence and fostering culturally safe health care environments. Without this, delays in care or avoidance of treatment, leading to negative health care outcomes, including increased morbidity and mortality, can occur (ANA, 2018).

An encouraging family environment and parental support have been shown to correlate with greater life satisfaction and less depression (Alegria, 2018). To optimize parents' support of their transgender children, and understanding of their challenges, health care providers with appropriate understanding of their needs and health disparities are essential. Providing educational materials to parents, such as the Parents ASSIST (Advancing Supportive and Sexuality-Inclusive Sex Talks) videos shared by recent researchers at the University of Pennsylvania (D. D. Flores et al., 2020), can also be helpful. Some of the parents in this study commented on the feelings and struggles of their significant other. Depending on whether or not the transition was male to female, or female to male, parental interactions with the child were strained or distant. Although the parent who was interviewed often commented on the other parent, their perspective was excluded, highlighting the need to encourage both parents to share their feelings. Additional efforts to recruit the other parent of the same child as well as siblings of transgender children/adults are essentially nonexistent and should be supported (Dierckx et al., 2016). Thus, further research is crucial to enhance and improve nursing and health care provider's knowledge related to holistic care for this population.

Finally, as leaders in health care change, there are many policy implications to consider. Nursing has historically cared for vulnerable populations and advocated for a just health care system. There is sufficient research that highlights the health and service needs of the transgender population. A major concern for people who identify as LGBTQ + is "stigma-related prejudice that can lead to further marginalization and social exclusion" (McCann \& Brown, 2019, p. 17). Advocating for policy change in bathroom usage, military service, sports, name recognition, or health care access and coverage are just a few areas where nursing can advocate for ethical policies that promote access, equity, quality, and cost.

\section{Conclusion}

The objective of this qualitative study was to begin to understand the experience of parents whose children undergo gender transition. The data analysis begins to shed light on the complex nature and struggles that parents face as they deal with the emotional and intellectual aspects of their child's transition. Because parents are seeking accurate, yet respectful information related to gender transition, schools, health care arenas, and counselors have to be aware that the entire family is in transition. While the rights of the transgender teen must be respected, focusing only on their needs alienates other family members and loved ones who are now going through a transition of their own (Alegria, 2018).

Stigmatization and discrimination continue to exist for families of transgender people and within the health care setting, causing unsafe feelings and mistrust of health care providers (Henriquez et al., 2019; Merryfeather \& Bruce, 2014). Nurses care for individuals in the context of families and communities and are obligated to provide safe and competent care. According to Merryfeather and Bruce (2014), "Without adequate understanding and experience, nurses may cause unnecessary and unintended harm when providing care for people who do not fit within culturally defined parameters of male and female" (p. 111). Thus, cultural awareness and competence are essential for nurses to 
provide appropriate and equitable care for transgender individuals and their families. Through an appreciation of the parent's experience, nurses can work to improve the health of the family as a whole.

Our notion of only two genders is challenged as we move forward in a health care environment where "gender identity and gender expression are continually evolving, representing the fluidity and complexities of gender" (Cicero \& Wesp, 2017, p. 99). As Cicero and Wesp (2017) note, "With social consciousness, visibility, and acceptance of transgender people increasing, more children and adolescents are asserting their gender identities. They are coming out as transgender at various ages during the course of normal child and adolescent development" (p. 97). The need to understand the parent's experience is critical to a positive transition for the individual, parent, and family. The findings raise awareness of the parents' perspective, provide a better understanding of the complex family issues that occur, provide nursing suggestions on how to continue to work to facilitate "healthy families," and promote cultural sensitivity.

\section{Acknowledgments}

The authors offer their sincere thanks to the parents and families who participated in this study.

\section{Declaration of Conflicting Interests}

The author(s) declared no potential conflicts of interest with respect to the research, authorship, and/or publication of this article.

\section{Funding}

The author(s) received no financial support for the research, authorship, and/or publication of this article.

\section{ORCID iD}

Linda D. Wagner (iD https://orcid.org/0000-0001-5482-8434

\section{References}

Alegria, C. (2018). Supporting families of transgender children/ youth: Parents speak on their experiences, identity, and views. International Journal of Transgenderism, 19(2), 132-143. https://doi.org/10.1080/15532739.2018.1450798

American Nurses Association. (2015). Code of ethics fornurses with interpretive statements. https://homecaremissouri.org/mahc/ documents/CodeofEthicswInterpretiveStatements20141.pdf

American Nurses Association. (2018). Position statement: Nursing advocacy for LGBTQ+ populations. https://www.nursingworld.org/practice-policy/nursing-excellence/official-position-statements/id/nursing-advocacy-for-lgbtq-populations/

Chick, N., \& Meleis, A. (1986). Transitions: A nursing concern. In P. L. Chinn (Ed.), Nursing research methodology: Issues and implementation (pp. 237-257). Wolters Kluwer.

Cicero, E. C., \& Wesp, L. M. (2017). Supporting the health and well-being of transgender students. Journal of School Nursing, 33(2), 95-108. https://doi.org/10.1177/1059840516689705
Colaizzi, P. (1978). Psychological research as the phenomenologist views it. In M. Vales \& M. King (Eds.), Existentialphenomenological alternatives for psychology (pp. 48-71). Oxford University Press.

Coolhart, D., Ritenour, K., \& Grodzinski, A. (2018). Experiences of ambiguous loss for parents of transgender male youth: A phenomenological exploration. Contemporary Family Therapy, 40, 28-41. https://doi.org/10.1007/S10591-0179426-X

Dierckx, M., Motmans, J., Mortelmans, D., \& T’Sjoen, G. (2016). Families in transition: A literature review. International Review of Psychiatry, 28(1), 36-43. https://doi.org/10.3109/09540261 .2015 .1102716

Eliason, M. (2017). The gender binary in nursing. Nursing Inquiry, 24, e12176. https://doi.org/10.1111/nin.12176

Flores, A. R., Herman, J. L., Gates, G. J., \& Brown, T. N. T. (2016). How many adults identify as transgender in the United States? https://williamsinstitute.law.ucla.edu/wp-content/uploads/ Trans-Adults-US-Aug-2016.pdf

Flores, D. D., Rosario, A. A., \& Bond, K. T. (2020). Parents ASSIST (Advancing Supportive and Sexuality-Inclusive Sex Talks): Iterative development of a sex communication video series for parents of gay, bisexual, and queer male adolescents. Journal of Family Nursing, 26(2), 90-101. https://doi. org/10.1177/1074840719897905

Gray, S., Sweeney, K., Randazzo, R., \& Levitt, H. (2016). “Am I doing the right thing?" Pathways to parenting a gender variant child. Family Process, 55(1), 123-138. https://doi.org/10.1111/ famp. 12128

Henriquez, N., Hyndman, K., \& Chachula, K. (2019). It's complicated: Improving undergraduate nursing students' understanding family and care of LGBTQ older adults. Journal of Family Nursing, 25(4), 506-532. https://doi. org/10.1177/1074840719864099

James, S., Herman, J., Rankin, S., Keisling, M., Mottet, L., \& Anafi, M. (2016). Executive summary of the report of the 2015 U.S. transgender survey. National Center for Transgender Equality. https://transequality.org/sites/default/files/docs/usts/USTSFull-Report-Dec17.pdf

Kirkpatrick, M., Esterhuizen, P., Jesse, E., \& Brown, S. (2015). Improving self-directed learning/ intercultural competencies: Breaking the silence. Nurse Educator, 40(1), 46-50. https://doi. org/10.1097/NNE.0000000000000092

Kuvalanka, K., Weiner, J., \& Mahan, D. (2014). Child, family, and community transformations: Findings from interviews with mothers of transgender girls. Journal of GLBT Family Studies, 10(4), 354-379. https://doi.org/10.1080/1550428X. 2013.834529

Landry, J. (2017). Delivering culturally sensitive care to LQBTQI patients. The Journal for Nurse Practitioners, 13(5), 342-347. http://doi.org/10.1016/j.nurpra.2016.12.015

McCann, E., \& Brown, M. (2019). Education and practice developments: Addressing the psychosocial concerns and support needs of LGBT + people. Nurse Education Today, 82, 15-20. https://doi.org./10.1016/j.nedt.2019.08.008

Meleis, A. I., Sawyer, L. M., Im, E. O., Hilfinger Messias, D. K., \& Schumacher, K. (2000). Experiencing transitions: An emerging middle-range theory. Advances in Nursing Science, 23(1), 12-28. 
Merryfeather, L., \& Bruce, A. (2014). The invisibility of gender diversity: Understanding transgender and transsexuality in nursing literature. Nursing Forum, 49(2), 110-123. https://doi. org/10.1111/nuf.12061

Nicol, P., Chapman, R., Watkins, R., Young, J., \& Shields, L. (2013). Tertiary paediatric hospital health professionals' attitudes to lesbian, gay, bisexual and transgender parents seeking health care for their children. Journal of Clinical Nursing, 22, 3396-3405. http://doi.org/10.1111/jocn.12372

Pinkerton, K. (2016). Katy Tierney: Leading CT provider of transgender care. Yale Nursing Matters, 16 (2), 21.

Saewyc, E. (2017). Respecting variations in embodiment as well as gender: Beyond the presumed "binary" of sex. Nursing Inquiry, 24, e12184. https://doi.org/10.1111/nin.12184

Schimmel-Bristow, A., Haley, S., Crouch, J., Evans, Y., Ahrens, K., McCary, C., \& Inwards-Breland, D. (2018). Youth and caregiver experiences of gender identity transition: A qualitative study. Psychology of Sexual Orientation and Gender Diversity, 5(2), 273-281. https://doi.org/10.1037/sgd0000269

Simons, L., Schrager, S., Clark, L., Belzer, M., \& Olson, J. (2013). Parental support and mental health among transgender adolescents. Journal of Adolescent Health, 53, 791-793. https://doi. org/10.1016/j.jadohealth.2013.07.019

Wahlig, J. (2015). Losing the child they thought they had: Therapeutic suggestions for an ambiguous loss perspective with parents of a transgender child. Journal of GLBT Family Studies, 11(4), 305-326. https://doi.org/10.1080/15 50428X.2014.945676
Wojnar, D. M., \& Swanson, K. M. (2007). Phenomenology: An exploration. Journal of Holistic Nursing, 25(3), 172-180. https://doi.org/10.1177/0898010106295172

Wright, L. M., \& Leahey, M. (2013). Nurses and families: A guide to family assessment and intervention (6th ed.). F.A. Davis.

\section{Author Biographies}

Linda D. Wagner, EdD, MSN, is an associate professor in School of Nursing, University of Bridgeport, Connecticut, USA. Her commitment to promoting healthy families is evident in her research focus on transitions and stigma. She has presented her research at the national and international level on stigma tool development and stigma in sickle cell disease, transitions and vulnerable populations, and students' experience of participating in a course abroad. Recent publications include: "Stigma in Adults With Sickle Cell Disease and Family Members: Scale Development and Pilot Study in the USA and Nigeria" in International Journal of Africa Nursing Sciences (2018, with R. Leger \& V. Odesina), "Stigma and Illness Uncertainty: Adding to the Burden of Sickle Cell Disease" in Hematology (2018, with A. Blake et al.), and "The Lived Experience of Having a Rare Medical Disorder: Hermansky-Pudlak Syndrome" in Chronic Illness (2017, with S. Christensen, M. Coleman, \& D. Appell).

Elizabeth Armstrong, DNP, CNE, is an assistant professor in the School of Nursing at the University of Bridgeport, Connecticut, USA. Her research interests focus on communities and families. Currently, she is coinvestigator/author for this research study focused on family health and transitions. This is her first publication. 